
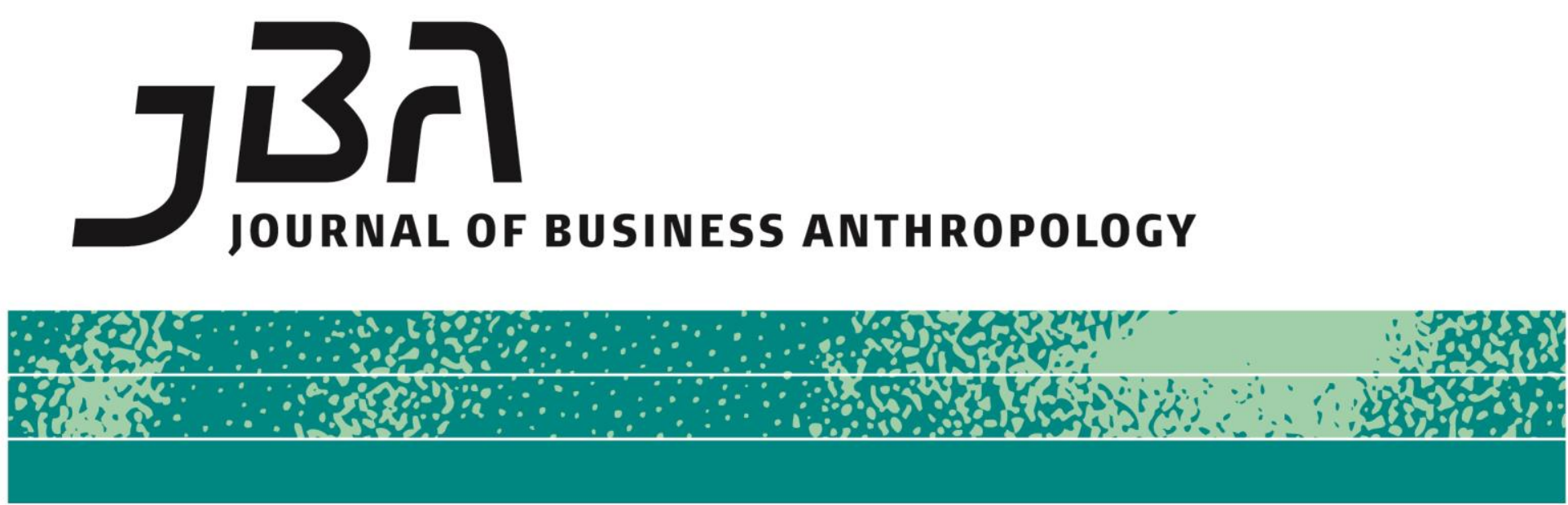

\title{
Transforming Hospital Culture by Changing Discourse
}

\author{
Elizabeth K. Briody
}

\section{Introduction}

Understanding "what's going on" within a particular cultural context has been an anthropological focus for over a century. Ethnographic methods have been a central part of the anthropological toolkit, employed to describe and explain the life ways and work ways of people across the globe. The exploration of cultural phenomena enables anthropologists to grasp and interpret why cultural groups think what they think, say what they say, and do what they do. Typically, anthropologists take a holistic approach considering such cultural features as symbols, belief systems, stories, work, and age and gender roles. Through comparisons of cultural phenomena, anthropologists are positioned to generalize, propose and test hypotheses, and figure out ways of solving cultural problems.
Page 1 of 22

JBA 3(2): 216-237 Fall 2014

(C) The Author(s) 2014 ISSN 2245-4217

www.cbs.dk/jba

\section{Discourse as a Sparring Topic for JBA}

One aspect of culture-discourse-reveals many insights about what prominent cultural processes exist, and how and why these cultural processes work as they do. The Concise Dictionary of Social and Cultural Anthropology defines discourse as "How people talk or write about a subject" (Morris 2012: 68). The transcription or text associated with what people say or write stands at the core of discourse analysis. My 
interest in discourse was rekindled in April 2014 when I participated in a workshop at the University of Hong Kong entitled Creative Engagements: Cross-Disciplinary Approaches to the Study of Business. Dixon Wong Heung-Wah and Brian Moeran, who led the workshop, paired participants together, based on some common interests but whose work experiences were quite different. As a business anthropologist and founder of Cultural Keys LLC, I conduct research for and consult with firms to help them with their organizational-culture and change issues. Wong and Moeran paired me with Dan Kärreman, Professor of Intercultural Communication and Management at the Copenhagen Business School. Both Kärreman and I conduct fieldwork inside organizations and use ethnography and discourse analysis as part of our methodological toolkit.

Many researchers have spent much of their careers examining talk and/or text: Basso (1972), Sacks, Schegloff and Jefferson (1974), Sherzer (1983), Drew and Heritage (1992), Boden (1995), and Wasson (2006)-to name a few. An important goal for researchers engaged in discourse analysis is to identify and delineate particular views, assumptions, and expectations-longstanding or emergent-affecting, or having the potential to affect, other aspects of the culture. My interests, however, are not only in cultural description and explanation, but also in organizational-culture change. I take a processual view of culture, and of discourse, which informs my perspective of cultural change. Just as I understand that discourse reflects culture at a given point in time, it also influences how culture evolves. Thus, discourse specifically, and culture generally, have implications for how I use analyses to guide culturaltransformation efforts (Briody, Trotter, and Meerwarth 2014). My article tees off Dan Kärreman's on organizational discourse.

\section{Kärreman on Organizational Discourse}

According to Kärreman, discourse can be separated into two key dimensions. On the one hand, discourse is concerned with linguistic interactions that are micro in nature and are of specific conversations and encounters. There is little intent to draw conclusions beyond the particular instance (Alvesson and Kärreman 2011). He refers to this local focus on discourse as little "d". By contrast, others emphasize the macro character of discourse that encompasses a prescribed "reality" grounded in history. This approach to discourse emphasizes a system of ideas rather than the day-to-day actions and activities of a particular group (cf. Foucault 1977). He terms this emphasis on discourse big "D".

Kärreman indicates frustration with this bifurcated interpretation and proposes "discursive pragmatism" as an alternate strategy for application to organizational phenomena. His theoretical approach is broader than the two he critiques. Indeed, he argues for greater inclusivity of cultural features (e.g., symbolism, structure of work, identity) to help inform the analysis. He proposes that organizational 
phenomena can be uncovered and understood by focusing on three features: talk, meaning, and practices. First-hand experience and analysis of what is said are required to identify general patterns, along with variation in those patterns.

Cultural or social anthropologists and linguistic anthropologists-among others-would readily applaud Kärreman's expanded view. Though not typically a topic of broad organizational interest, he contrasts the institution of marriage (big "D") with that of a wedding (little "d"). Marriage as an institution includes some commonly overlapping themes and patterns (e.g., it involves two people, is associated with a long-term commitment). Yet, marriage as a concept is different from an individual wedding. Weddings take many ceremonial forms, sometimes engage clergy, and vary in expression of cultural beliefs. Kärreman suggests that discursive pragmatism enables 1) an examination of the relationship among talk, meaning, and practice in a given instance (say, of a wedding), and 2) comparison across instances. Through an investigation of specific patterns, the elucidation of a general pattern(s) (of marriage the institution) is possible.

\section{Briody on Organizational Discourse}

Kärreman's theoretically-oriented article was an inspiration for my empirical and applications-oriented case study, in which I present a conscious effort to change the organizational culture of a hospital by changing the discourse in staff-patient interactions. The attempted change in hospital culture was prompted by the emergence of the highly publicized patient-experience paradigm operating within the U.S. health care sector. The patient experience was a relatively recent target for focus by American hospitals, clinics and physician practices. Health care delivery stood to improve if provider and patient worked well together. Table 1 compares the categories of discourse in the case study with those in the Kärreman example.

Table 1: Discourse Comparison Using Author Examples

\begin{tabular}{|c|c|c|}
\hline Discourse Category & Briody & Kärreman \\
\hline Big "D" & $\begin{array}{c}\text { Patient-Experience } \\
\text { Paradigm }\end{array}$ & Institution of Marriage \\
\hline Little "d" & Staff-Patient Interactions & Weddings \\
\hline
\end{tabular}

Administrators from one large American hospital hired me to help them improve their patient satisfaction scores, and ultimately the overall experiences of patients during their hospital stays. The case is complex. A new communications technique was introduced into the culture with the goal of enhancing the hospital's competitive position in the 
marketplace. The technique was mandated for use in staff-patient interactions to help improve the patient experience. In the course of observing how its implementation was proceeding, I discovered alternative forms of discourse in use. The case includes the differentiated reactions to the new technique, proposes an explanation for them, and ties them back to the existing literature.

Much of the above would be considered a typical or usual approach to fieldwork, analysis, and write-up. There is a dual focus on description and explanation. New theoretical ideas are advanced and old ones expanded or critiqued. However, for professional anthropologists, the work with the client continues. The focus shifts from the analysis to the important question: What should the organization do now?

Organizational leaders hire anthropologists and others who engage in consulting because they seek new approaches, perspectives, designs, and answers to troubling issues. In due course, my team and I recommended further changes in both the mandated and actual discourse patterns to get closer to the hospital's objective of improving the patient experience. I review some of these recommendations and show the value of relating both the findings and recommendations to big " $\mathrm{D}$ " and little " $\mathrm{d}$ ".

\section{Background}

Patient satisfaction and engagement have been among the hottest topics in U.S. medical care for quite some time. Beginning in 2002, the federal government initiated work on a standardized, nation-wide survey to gather patient views of their hospital care. Results from the HCAHPS (Hospital Consumer Assessment of Healthcare Providers and Systems) survey are publicly reported and have contributed to the calculation of incentive payments that hospitals have received since 2012. Hospitals have been motivated to tackle low scores because of new rules related to government reimbursement as a result of the Affordable Care Act. HCAHPS emphasizes the quality of staff-patient interactions including nurse communication, doctor communication, responsiveness of hospital staff, pain management, communication about medicines, and discharge information. ${ }^{1}$

Over the last decade, a variety of organizations began focusing their efforts on the concept of the patient experience, and ultimately cultural change. The Beryl Institute, emphasizing patient interaction and communication, crafted this definition of the patient experience in 2010: "The sum of all interactions, shaped by an organization's culture, that influence patient perceptions across the continuum of care."2 The

\footnotetext{
${ }^{1}$ www.cms.gov/Medicare/Quality-Initiatives-Patient-AssessmentInstruments/HospitalQualityInits/downloads/HospitalHCAHPSFactSheet201007 pdf

${ }^{2}$ http://www.theberylinstitute.org/?page=DefiningPatientExp
} 
Institute for Healthcare Improvement identified five key drivers of the patient and family experience associated with inpatient hospital stays. Those drivers included "leadership, staff hearts and minds, respectful partnership, reliable care, and evidence-based care" (Balik, Conway, Zipperer, and Watson 2011). The non-profit Association for Patient Experience has stressed "patient-centeredness" and is "dedicated to enhancing the clinical, physical and emotional healthcare environment, ensuring that care is delivered with compassion and empathy." ${ }^{3}$ Consulting firms and the popular press have picked up on this topic (Feirn, A., D. Betts, and T. Tribble 2009; Versel 2014; Merlino and Raman 2013) and have described priorities and suggestions for achieving improved patient experiences based on the patient perspective.

A training tool, created by the Studer Group, has been employed to help improve verbal and non-verbal communication within hospital settings. The tool is known as AIDET, an acronym reflecting five fundamentals of staff-patient communication:

A = Acknowledge the patient (e.g., smile, make eye contact)

I = Introduce yourself to the patient

$\mathrm{D}=$ Indicate the duration (e.g., of tests, discharge process)

$\mathrm{E}=$ Explain (e.g., reason for the visit, initial diagnosis) and ask if there are any questions

$\mathrm{T}=$ Thank the patient

The Studer Group asserts that the use of AIDET with patients and their families can "anticipate, meet, and exceed the expectations of the customer and reduce the anxiety of the patient." ${ }^{4}$ Hospitals across the U.S. have been implementing AIDET in an effort to improve the quality of staff-patient interactions, hoping to enhance their overall HCAHPS scores and in the process, help their culture change.

A Southern U.S. hospital, referred to here as ABC Hospital (a pseudonym) was exposed to AIDET at an internal Leadership Retreat in September 2012. The presenter, a member of ABC's middle management and the head of its in-house "university" (i.e., training center), explained, "Some of our HCAHPS scores are still showing troubling trends," and then introduced AIDET as a solution to improve communication and the patient experience. Over the next twelve months, this individual worked tirelessly with her staff and the cross-functional Patient Experience Team to implement AIDET. Hospital leaders received some training in the technique, followed by employees. Participants were told that the hospital's poor HCAHPS scores were evidence of a low-performing hospital culture and one that would benefit from AIDET. However, staff surveys early in 2013 already revealed that an "AIDET reboot" was necessary, since the initiative had not been adopted hospital-wide.

\footnotetext{
${ }^{3}$ www.patient-experience.org/About.aspx

${ }^{4}$ https://www.studergroup.com/who-we-are/glossary-of-terms
} 
Additional efforts were carried out by the Patient Experience Team to raise AIDET awareness before AIDET observations and coaching took place on the nursing floors in summer 2013.

\section{Data and Methods}

The data for this article were collected as part of a 15-month research project with ABC Hospital in 2012-13. The overall project focus was the improvement of patient hospital experiences, including the flow of patients through the hospital setting. My six-member team and I conducted 101 staff interviews, attended 51 staff meetings, and engaged in 46 observations of staff-patient-family member interactions.

This article focuses on the AIDET initiative. In particular, it targets reactions to AIDET by hospital staff and observations of AIDET use during interactions between staff and patients. Staff reactions were gathered over the course of several months-primarily in individual discussions and at meetings-and became an important part of the field record. The observations, conducted by the same researcher, took place over a onemonth period during summer 2013. Five hour-long observations lasting between 15 and 115 minutes (57 minutes on average) occurred in four different hospital units. The researcher-observer shadowed staff, participated in, "Environment of Care" rounds, and attended a staff meeting.

We used both content analysis and discourse analysis to make sense of the data set. We identified themes and patterns of the data set's content, coding and interpreting it, and selecting representative examples as highlights. Discourse analysis was employed when we focused on micro situations such as brief interactions involving two to three people. With this technique we paid attention to such factors as the terminology, syntax, and inflection of participants in the interaction, along with their occupational role and status, and purpose for being there. Numerous other hospital meetings, events, discussions, and observations informed our analysis.

\section{Perceptions of AIDET}

\section{Pre-Observation Phase}

Staff expressed a wide range of views about AIDET in the weeks and months prior to the AIDET observations. Some staff offered positive assessments that indicated the importance and relevance of this communication technique for their work:

- "... when applied correctly it can improve communication between patients and caregivers."

- "It's a good reminder of the basics - the basic way to talk to people." 
- "It's part of our life (at ABC)."

- “... (it) helps patients understand who you are and makes them feel welcome."

Other members of the staff offered a perspective that was ripe with criticism:

- "Just another stupid customer service program - won't be effective until our culture changes."

- "Reviewed several weeks ago and don't remember the material."

- "Not applicable to my job duties."

Still others mentioned AIDET implementation challenges as attempts were made to integrate AIDET into hospital culture such as "I like it but I don't think we need to be waking the patients up to do AIDET" or "I think we need to stay after it; we need to keep it in front of people."

\section{At Time of Observation}

Given the mixed perceptions of the AIDET initiative, researchers conducting the study emphasized to staff that their AIDET observations reflected aspects of a new ABC Hospital culture, not the old one. Researcher statements corresponded with the cultural change initiative in which the hospital was engaged since hiring me in summer 2012. In the new hospital culture, AIDET was a "tool" to help "better interaction with the patient, where the patient feels that people really care." Researchers explained that the observations were designed to "give pointers" and "feedback," and were offered "just as a way to help coach on how to improve our AIDET practice." They also told staff: "It's not a test," "This isn't a gotcha thing," or "(It) isn't meant to be punitive." Indeed, they argued, "We're here to help. We want you to succeed and we know that you will."

Nevertheless, staff repeatedly expressed concern about doing AIDET correctly. When it was time to show proper AIDET use, staff statements suggested nervousness and apprehension. These four brief exchanges are emblematic of the reactions by staff members in clinical roles.

1. Staff member to observer: "Oh, pick me. I volunteer. I can use all the help I can get." He laughs.

2. Staff member to observer: "Show time!" She laughs as she walks into a patient's room, with observer following behind.

3. Staff member to observer: "Okay, what do I need to do for this?"

Observer: "Just be yourself." 
Staff member:

4. Staff member to observer:
"Got it." She laughs.

\author{
Stating off the cuff what AIDET \\ means. \\ "Acknowledge, Introduce, Duration, \\ Explanation, Thanks! Did I pass?” \\ She laughs.
}

Three attributes of these exchanges are consistent with and reflect staff member unease. First, in all four exchanges, staff members try to make a joke and then laugh. Second, the staff members use certain colloquialisms or specialized jargon (e.g., "Show time," “Got it!"), phrases that are an effort to both build rapport and equalize the asymmetrical relationship with the observer. Finally, some staff members explicitly request reassurance from the observer that they successfully demonstrated knowledge and use of AIDET (e.g., "Okay, what do I need to do for this?" "Did I pass?"). Staff seemed to understand that the observation was more like an exam, rather than advising or coaching.

\section{Observations of Staff-Initiated Interactions}

The two exchanges that follow represent divergent ends of the spectrum. In both cases, staff members initiate interactions with patients/family members. In both cases, staff members have a task to complete involving the patient. At the same time, the patient/family member tries to use the interaction to secure something of value (e.g., pain relief, cheerful conversation) for their own benefit.

\section{AIDET Not in Use}

Example 1 is an encounter between a Patient Care Assistant (PCA) and a family member. A few but not all AIDET elements are part of the interaction. The PCA greets the patient (A - Acknowledge) and mentions (E - Explain) why she is in his room. While the PCA does not specify how long she would be there (D - Duration), if she were only there to take the patient's temperature, the patient/family member could have estimated it would be a short period of time.

\section{Example 1: AIDET and Taking Vital Signs}

PCA:

Family Member:

PCA:

Family Member: "Oh." that."
"Hello Mr. Smith. Just here to take your temperature." "Do you think you could get his pain medicine? He said he was hurting."

"I'm so sorry. I'm not a nurse. A nurse has to give him 
PCA:

Takes patient's temperature. “98.2 - That's good. Remember! Don't try to get up. We've got that bed alarm on." PCA walks out of the room and enters another patient room down the hall.

The remaining two AIDET elements are omitted. First, the PCA does not introduce herself (I - Introduce). While it is unclear if the patient knew the PCA, the visiting family member appears not to have known her. Therefore, an introduction would have been appropriate. Second, the PCA does not end the interaction using the closing ( $\mathrm{T}$ - Thank you!). However, most egregious about this interaction is the PCA's disregard of the appeal for pain medication. The PCA does not offer to find a nurse to address the request. While it may be hard to fault the PCA on the basis of AIDET (since responding to a patient/family member query is not explicitly an AIDET element), the PCA's statement comes across as inappropriate and unfeeling. Indeed, this type of staff inaction to a "customer" request is often highlighted in post-hospital-stay patient surveys-inaction that AIDET is supposed to allay.

\section{AIDET in Use}

In another exchange (See Example 2), all AIDET elements are integrated into this interaction between a Hostess from the hospital's food service and a patient. The hostess acknowledges (A) the patient and introduces (I) herself. She explains (E) the reason for her visit. Though she does not explicitly indicate how long (D) she will be in the room, the patient would know that the duration of her visit would be brief. She thanks (T) the patient before leaving. The AIDET elements seem to lead to a positive reaction from the patient. Indeed, the rapport between the two individuals appears to be pleasant and linked to a prior interaction in which the hostess offered a meal suggestion.

\section{Example 2: AIDET and the Meal Tray Pickup}

$\begin{array}{ll}\text { Hostess: } & \text { "Hi! It's Sarah from Dietary. May I come in?" Hostess } \\ & \text { waits for response before entering the room. } \\ \text { Patient: } & \text { "Sure." } \\ \text { Hostess: } & \text { "I'm just here to pick up your tray. How was your } \\ & \text { lunch?" } \\ \text { Patient: } & \text { "Great! Thanks so much for suggesting that." } \\ \text { Hostess: } & \text { "I'm so glad. Thank you!" }\end{array}$

The integration of AIDET into the daily work of the hospital employees was particularly noticeable in support services. Employees in both dietary and cleaning services incorporated the elements of the AIDET 
acronym into their interactions with patients. They experienced intense training and one-on-one coaching to ensure that they were proficient in it. A leader in cleaning services described a few different ways in which to reinforce AIDET:

AIDET is one of many tools we use. The companion piece is the 10step cleaning process. AIDET has to be hand-in-hand with it. At our last department meeting, we focused on what not to do. We made an un-AIDET video-how you don't engage the patient! It was hilarious. We then asked, What would we do differently? ... We did print up the AIDET cards (to keep as a reminder on our cleaning carts).

The high level of concern associated with the AIDET observations was consistent with a hospital culture in which the task, and not the patient, was the primary focus, and in which collaboration was infrequent. While some hospital functions embraced the use of AIDET, other functions indicated their opposition to using it. We initially thought AIDET would be valued when staff-patient encounters were purposeful, well defined, and task-focused. Picking up a dining tray or cleaning a patient's room were tasks that fit these criteria. On the other hand, taking vital signs or drawing blood also were well defined and time-bound tasks and yet AIDET was never consistently integrated into those interactions.

Our observations also revealed that AIDET use corresponded with a staff-initiated interaction. Staff approached patients with a particular task in mind-one that was part of their job responsibilities. The statements staff made or questions they asked were intended to capture information that they needed to complete their daily tasks. We found that AIDET could certainly be employed effectively to guide the interaction and enable the staff member to "get the job done" in a way that was enjoyable, caring, and effective. We observed no instances of AIDET use when a patient initiated the interaction.

\section{Observations of Patient-Initiated Interactions}

Of course, patients/family members ask questions, make statements, and exhibit certain behaviors directed at hospital staff. Asking for simple instructions, how long something might take, what the next steps would likely be, and when something might happen are frequent examples of questions that are posed. Commenting on some aspect of the hospital environment, personnel, tests, or food also represent ways in which information is shared. Finally, patients/family members may engage in certain actions or non-verbal behaviors to communicate with hospital staff.

Not surprisingly, we discovered that many staff-patient encounters did not follow the AIDET model. For example, when patients initiated interactions with hospital staff, new elements appeared that were not 
explicitly included in AIDET. Sometimes these new features occurred alongside one or more of the AIDET elements. Most importantly, the interactions did not have a proscribed framework as with AIDET. The interaction had the potential to take different paths, depending on the topics or issues introduced by the patient and the response to them by the staff member.

\section{Empathetic Engagement}

When patients require the help of clinical staff, they may communicate non-verbally (e.g., use patient call button, grimace to indicate pain). Such forms of communication can supplement and reinforce verbal communication, or replace it. Example 3 captures the largely non-verbal aspects of the patient's communication in comparison to the combined verbal and action-oriented responses of the nurse. A rhythm seems to emerge between patient and nurse with patient actions followed by nurse responses. This example demonstrates the active role played by the patient in the exchange, despite both the language barrier and poor health.

\section{Example 3: Call Button Responsiveness}

Patient: $\quad$ Uses call button to signal help is needed.

Nurse: $\quad$ Sees call light on outside patient's room and enters. "Mrs. (Rivera)? It's Sandy. What can I do for you? You want to lie back? On your side?"

Patient: $\quad$ Says something in broken English.

(Observation notes: It is evident the patient is uncomfortable.)

Nurse: $\quad$ Adjusts the patient's pillows and helps patient get on her side. "Okay, I want to make sure you can reach everything you need. TV control is here. Call button here. Are you done with your breakfast because I can take your tray for you and then move that table to give you a little more room? That way you won't be so cramped in bed." Nurse lifts the dietary tray and moves the bedside table. "Okay, Mrs. Rivera. I'm going to leave your light off. I will be back in a little bit with your medications. Please call us if you need anything else."

Several features are incorporated into the nurse's approach to the patient. First, the nurse uses two elements of AIDET when she comes to the patient's bedside: A - Acknowledge and I - Introduce. Second, other 
elements appear as the interaction evolves. The nurse is proactive in inquiring about how she can be helpful. She responds in an understanding way to the patient, suggesting options to improve the patient's comfort. The nurse then helps the patient change positions and fluffs the pillows, strategies that may offer solutions-at least in part-to the patient's pain or discomfort. Similarly, the nurse purposely rearranges the controls for the TV and call button to be within the patient's reach and turns the lights off. Finally, the nurse states she will return later with medications and reminds the patient use the call button "if you need anything else." Thus, we note three additional elements that emerged in this clinical interaction: proactive inquiry, responsive understanding, and solution development and implementation. These features occur more than once during the interaction.

\section{Task Intensity}

Just as there are encouraging words and helpful actions that can resonate with patients, the opposite also occurs. A staff member's reply to a patient may be interpreted as brusque, unkind, or worse. There may be understandable explanations for that behavior (e.g., high patient-to-staff ratios, higher-than-usual patient acuity requiring more time per patient). Such conditions could contribute to an excessive focus on getting the various tasks done, rather than problem solving with patients over their particular situations. Example 4 documents the observation of a physician-patient interaction that immediately followed a patient request (first to the nurse and then the physician) to transfer to a different hospital for further treatment.

\section{Example 4: Transfer Request Denied}

Physician: $\quad$ Walking into room: "Hello Mrs. Krajeski. I understand you want to go to Mayo. I will send a note to the Rehab physician and make him aware of that."

Patient: "I was really hoping to go from here, instead of going to Rehab first. They know me at Mayo (Clinic). I've been there before and they know my history. I'm also worried about my records. How will Mayo get them? Can they get them from Rehab?"

Physician: "Oh, that part is very, very easy. They will send you a release form. You can take that to the Medical Records Department and they can burn your records onto a CD for Mayo. Here's what I'll do on my end. I'll get your paperwork ready for you to be discharged. It will probably take about an hour. And I'll let the Rehab physician know you're planning Mayo. Let me get started on that. Sound good?" 


$\begin{array}{ll}\text { Patient: } & \text { "I guess." } \\ \text { Physician: } & \text { Walks out of the room and turns out the patient's light. } \\ \text { Patient: } & \text { "No, leave it on! Why would you do that? The light } \\ & \text { was on when you came in!" } \\ \text { Physician: } & \text { "So sorry." Physician turns light back on and then } \\ & \text { walks into the hallway. }\end{array}$

The patient's nurse is coming out of another room.

$\begin{array}{ll}\text { Physician: } & \text { "Get room } 21 \text { ready to go." } \\ \text { Nurse: } & \text { Looking surprised: "Where's she going?" } \\ \text { Physician: } & \text { "Rehab." } \\ \text { Nurse: } & \text { I thought she wanted to go to Mayo?" } \\ \text { Physician: } & \text { "She's going to have to arrange that herself." }\end{array}$

The physician is already acquainted with the patient's request upon entering the room. He employs two aspects of AIDET during his interaction; he acknowledges (A) the patient by name, and mentions how long the discharge process will take (D). We also can assume that the two already knew each other (I). The physician hears the patient's request repeated, but sidesteps answering it directly. Instead, he redirects the patient's focus to a secondary concern-the transfer of the patient's medical records-making it clear that the responsibility for the transfer lies with the patient. He then attempts to get the patient to agree with the transfer denial. Thus, we see a disregard for the patient's request without an appropriate explanation (E). The patient grasps the physician's lack of accommodation and reacts angrily, accusing the physician of intentionally turning off the room light. Even though the physician apologizes, there is no sense that the patient either believes him or accepts his apology. No thank you (T) is offered. The nurse's surprise at the physician's decision appears to validate the patient's displaced anger. In Example 4, the interactions between the patient and physician, and between the physician and nurse, illustrate physician power and authority without accountability.

Sometime after the observation concluded, the observer received a follow-up email from the physician stating, "We were in surge that day so physicians were in a crunch to discharge patients. Easier to discharge to Rehab than discharge to Mayo." A "surge" condition as the backdrop of these interactions provides some context for understanding the physician's decision. During a surge, there is a rise in the number of patients needing medical care and a hospital bed, so much so that there are insufficient beds on the nursing floors to accommodate the influx.

However, the physician comes across as indifferent and insincere. The physician's focus is single-minded and ethnocentric: to move the patient quickly to another healthcare facility, thereby temporarily reducing his own workload and freeing up a bed. His actions are deliberate and do not take the patient's views into account. The 
physician's interactions with both the patient and nurse are largely transactional. Neither has any recourse and must deal with the aftermath of the decision: the patient leaves the hospital upset and dissatisfied, while the nurse likely remains skeptical and untrusting of the physician's priorities. The physician's lack of empathy, compounded by an unwillingness to grant the patient's request or explain why the request could not be filled, result in a "lose-lose" situation for the patient and the nurse, as well as his own and the hospital's reputation.

\section{Departmental Differences in Staff-Patient Interactions}

Hospital departments approach interactions with patients differently. I noted that the support services' department of the hospital eagerly adopted the use of AIDET in its interactions with patients. While this effort has required ongoing employee training and follow-up, it has led to some positive benefits. First, AIDET has enabled support services' employees to converse effectively with patients/family members as they perform their jobs. Many employees report being at greater ease in interacting with patients because of the AIDET format. Second, support services' employees have discovered that their patient customers appreciate what they do for them-whether taking their meal orders or cleaning their bathrooms (See Example 2). Third, patient satisfaction with support services has improved, leading to overall improvement in the hospital's patient experience scores.

Nursing, and many other departments did not integrate AIDET into their interactions with patients. The leader of the hospital's in-house university who spearheaded the AIDET initiative pushed hard for its adoption within nursing. The reaction from nursing was mixed but largely negative, with many feeling that some of the AIDET elements, including I - Introduce and T - Thank you, were inappropriate as staff interacted with the same patients several times over their shifts. While it was not our purpose to examine the extent to which nursing routinely performed the AIDET elements in their interactions with patients, our observations revealed that many did not (See Example 1); the same pattern is apparent in the physician-patient interaction (See Example 4). In those two examples, staff members focused on those tasks that were required and on which their performance was assessed. At ABC Hospital, the delivery of patient care incorporates those must-do tasks, but does not routinely encompass the relationship component.

However, our observations also showed that many nurses, patient care specialists, and techs employed elements in their patient interactions that were not explicitly a part of AIDET (See Example 3). The listening, empathy expressed, problem solving, and other similar attributes extended well beyond the information-provision content of AIDET. The Empathetic Engagement Model had powerful effects on patients. Many in nursing would listen to their patients, talk with (not to) them, make them 
as comfortable as possible, and engage them in their own care-while still getting their clinical tasks accomplished. In fact, these individuals integrated their knowledge of nursing with their desire to help people to create a patient-centric environment.

\section{Discussion}

Value in Integrating Forms of Discourse

The current body of knowledge regarding the discourse of the patient experience (big "D") has evolved over the last several years to highlight the salience of a positive hospital stay. In essence, a positive patient experience is an ideal goal on which many hospitals set their sights. The literature emphasizes a variety of "drivers" from the patient perspective to try to achieve such a goal. Included among them are the importance of excellence in connection, communication, and partnership between hospital staff and patients, dependable and transparent care, and employee engagement, to name a few (Merlino and Raman 2011; Balik, Conway, Zipperer, and Watson 2011; Feirn, Betts, and Tribble 2009). That ideal goal is now tied to some standardized metrics, making it possible to compare across the health care sector, reward top-performing hospitals, and penalize low-performing ones.

This case study draws attention to the verbal and non-verbal behaviors related to inpatient care at ABC Hospital. These behaviors represent day-to day staff-patient interactions, or local instances of little "d". The interactions are associated with a range of viewpoints and expectations by patients and staff. Unlike big " $\mathrm{D}$ " discourse, there is no consensus at $\mathrm{ABC}$ Hospital about what the patient experience is or should be, how important it is to patient care, or any agreed-upon set of best practices. Instead three distinct interaction models were observed during the research period: AIDET, Empathetic Engagement, and Task Intensity. Characteristics of the three models are presented in Table 2.

These models not only characterize three distinctive forms of staffpatient interactions, they are indicative of the ways in which staff perform their duties. All three models necessarily include the staff's work activities, but give higher or lower prominence to the relationship side of patient care. AIDET has a prescribed structure to assist staff in delivering a service to patients/family members, while at the same time improving patient rapport and understanding. By contrast, Task Intensity stresses the planning and execution of the task, largely independently of a patient relationship. Finally, Empathetic Engagement incorporates service delivery in a responsive and compassionate way as it engages the patient in his/her own care. 
Table 2: Model Characteristics of Staff-Patient Interactions

\begin{tabular}{|l|c|c|c|}
\hline $\begin{array}{l}\text { Staff Qualities at } \\
\text { ABC Hospital }\end{array}$ & AIDET & $\begin{array}{c}\text { Empathetic } \\
\text { Engagement }\end{array}$ & Task Intensity \\
\hline $\begin{array}{l}\text { Quick and effective } \\
\text { rapport building }\end{array}$ & High & High & Low \\
\hline Proactive inquiry & Perhaps & High & Low \\
\hline $\begin{array}{l}\text { Efficient execution } \\
\text { of prescribed tasks }\end{array}$ & High & Perhaps & High \\
\hline $\begin{array}{l}\text { Initiation of two- } \\
\text { way information } \\
\text { flow }\end{array}$ & Perhaps & High & High \\
\hline $\begin{array}{l}\text { Use of status and } \\
\text { power for own } \\
\text { benefit }\end{array}$ & Low & Low & High \\
\hline $\begin{array}{l}\text { Addressing } \\
\text { questions and } \\
\text { concerns } \\
\text { satisfactorily }\end{array}$ & Low & Perhaps & Low \\
\hline $\begin{array}{l}\text { Collaborative } \\
\text { problem solving }\end{array}$ & Perhaps & High & Low \\
\hline Learning for future & Perhaps & High & Low \\
\hline
\end{tabular}

Drawing these distinctions across the three models is a useful way of understanding the context in which the patient experience plays out. This analysis sheds light on the variation that exists locally (little "d") while contributing to the knowledge base of the broader patientexperience paradigm (big "D"). These two categories of discourse inform an understanding of each other-an understanding that would not exist had we not explored the relationship between the two. For example, from the three models presented here, it is possible to identify core components of the patient experience such as task focus (e.g., completion, speed, effectiveness) and the relationship component (e.g., understanding, sharing, problem solving). A robust combination of these two elements appears to affect patient perceptions of their hospital stay in a positive way. At the same time, the broader paradigm on the patient experience benefits by becoming better defined and articulated, serving as a more powerful beacon in guiding hospital teams in patient care.

Of the three models, I argue that Empathetic Engagement represents the gold standard for the patient experience. It has a holistic focus, attending to the body, spirit, and the connection between the two. AIDET, too, is a valuable model that can contribute to a positive patient experience as it aids staff members in their job duties. A cheerful, interested staff employing AIDET can be a strong source of patient support. These models can reinforce each other-with Empathetic Engagement active when patients initiate an interaction through a query 
or statement, and AIDET when a staff member initiates an interaction in the fulfillment of job duties. Patients interpret behavior associated with the Task Intensity Model as the least effective of the three models. Because this model concentrates so completely on the job requirements, its focus has the effect of overshadowing expressions of care and concern that patients often seek.

\section{Value in Discursive Pragmatism}

Kärreman's discursive-pragmatism strategy is attractive for three important reasons. First, his emphasis is not simply on verbal communication or the discourse itself. Instead, he considers talk, meaning, and practices together as a set. All provide specific kinds of insight into the discourse under consideration.

Second, he indicates that the interrelationships among the talk, meaning, and practices offer a more comprehensive understanding of the discourse than would each of these elements taken separately. Applying discursive pragmatism to Example 2, we can see the talk ("It's Sarah from Dietary. May I come in?"), the behaviors associated with it (Hostess waits for response before entering the room), and the interpretation of both the talk and the behaviors (patient indicates gratitude for the meal suggestion). Together they indicate that rapport has been built, the hostess' tasks have been accomplished and validated, and a pleasant encounter between hostess and patient has occurred.

Third, Kärreman's strategy entails the collection and analysis of numerous instances of particular interactions (little " $d$ ") to allow "a better foundation" as the general patterns (big " $D$ ") take shape. This dimension of his strategy is consistent with my approach. If I had not analyzed the AIDET observations, I would neither have known about the variation in departmental acceptance, nor about AIDET's strong connection to staffinitiated interactions with patients. Furthermore, I would not have been able to explain opposition to AIDET-whether because AIDET did not offer a sufficiently open and flexible process to allow for a robust two-way communication flow, or because at least some hospital staff were so task focused that building rapport with patients had no chance of being a priority. Without an understanding of the commonalities and variation in staff-patient interaction models, it would not have been possible to validate and specify core components of the broader patient-experience paradigm (big “D”).

\section{A Friendly Critique}

I also have concerns that Kärreman's discursive pragmatism does not go far enough. It is important to ask where the key stimuli for improving the patient experience are situated. From this data set, the stimuli originated 
outside $\mathrm{ABC}$ Hospital, that is, there was an external environmental influence involved. U.S. health care costs were continuing to skyrocket all the while tens of millions of Americans had no health care coverage. During the preparation and passage of the Affordable Care Act, the patient experience was emerging as one of the many aspects of the legislation that necessitated change in hospital culture (See Chart 1). Discursive pragmatism does not seem to focus on the external environment as a source of or factor in organizational-change processes.

\section{Chart 1: Externally Driven Change in Local Hospital Discourse}

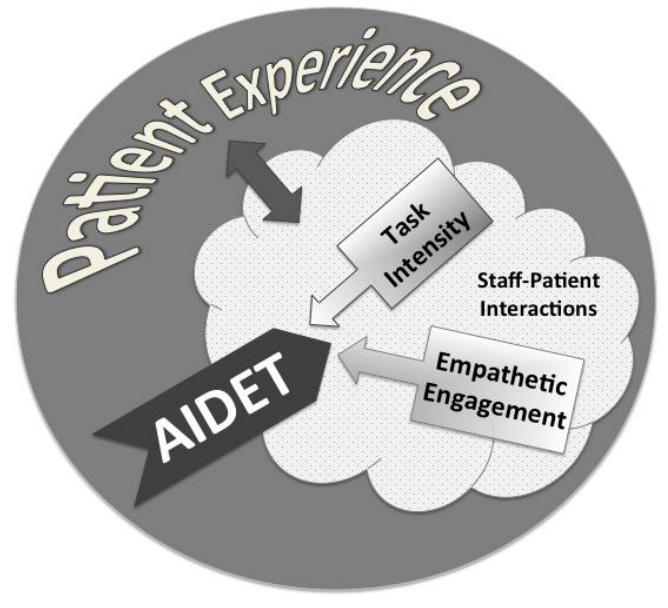

AIDET was developed and disseminated as a mechanism to improve the patient experience, and indirectly to motivate change in hospital culture. It targeted change in discourse, and through discourse, behavior in staffpatient interactions. Although AIDET met with resistance at ABC Hospital from most hospital departments, resulting in the discovery of the Task Intensity and Empathetic Engagement Models, it enjoyed some success in support services. AIDET raised hospital awareness of the external thrust to become more patient-centered or suffer the reimbursement consequences. Finally, AIDET as a focal area for this study, led to an improved understanding of its value in staff-initiated interactions and its potential to serve as a communications bridge to the Empathetic Engagement Model.

The discursive pragmatism strategy largely omits the culture concept. It is not clear to me why that is the case or must be the case. Perhaps Kärreman preferred to focus on talk, meaning, and practices to the exclusion of other cultural phenomena? Perhaps the way in which he defines culture is somehow at odds with the discursive pragmatism strategy? Perhaps management scholars consider the culture concept to be passé? What I suggest is that local examples are situated in specific organizational cultures (paralleling little "d" parlance) that are characterized by distinctive structures and dynamics. These organizational cultures influence and are influenced by aspects of the 
broader culture (a parallel to big " $\mathrm{D}$ ") and depicted in Chart 1 by a twoway arrow.

The organizational culture of $\mathrm{ABC}$ Hospital informed my perspective of the local discourses and their relationship to the broader patient-experience paradigm. An external source-patient surveys-showed the hospital getting hammered on its low HCAHPS scores. Our 15 months of fieldwork and years of direct experience (via the six members of my research team) helped explain why. Key obstacles faced by the hospital included:

- Task focus: work practices devoid of engaging patients and colleagues collaboratively and empathetically

- Fear of criticism: concerns about "scrutiny" and the potential for poor evaluation on performance

- Resistance: opposition often when proposed actions divert from status quo

- Departmental "silos:" optimization and collaboration occurred within rather than across hospital units so that benefits did not accrue to the hospital as a whole

- Inappropriate incentives: expectations, metrics, rewards, and sanctions were not in place to drive cultural change.

Many of these obstacles were present in some of the staff perceptions during the Pre-Observation Phase of AIDET implementation, the staff remarks immediately before the AIDET Observations began, and Examples 1 and 4.

In a similar way, my research team identified well-functioning aspects of selected parts of the hospital's culture; work groups and departments varied in their association with these enablers, or positive cultural processes. When present, these enablers helped explain some of the staff reactions in the period prior to and during the AIDET observations, as well as staff behavior in Examples 2 and 3. Among these enablers were:

- Information sharing: providing knowledge, insights, and lessons freely to others

- Problem solving with high energy: figuring out ways to address issues quickly and creatively

- Fostering relationships: building ties characterized by collaboration, cooperation, and mutual exchange

- Pride in work: interest, energy, and effort devoted to the successful accomplishment of work goals

- Repetition: continual reiteration of key goals and strategies to break free of the "flavor of the month" pattern.

Knowing the salient cultural attributes of an organization allows researchers to examine the findings for consistency with the broader organizational culture, as well as validate results. When the cultural 
dimension is not depicted, the discourse analysis cannot be as accurate or complete because it has neither been situated in its internal (e.g., hospital) context, nor in the wider cultural (e.g., American) context.

Finally, I would like to end my article with a sense of what it is like to use discourse analysis skills for assisting organizations as they cope with change. Let's say that you are now in my shoes at ABC Hospital.

- What are the key recommendations from your discourse analysis of staff-patient interactions?

- How do you advise the head of the in-house university, as well as hospital leadership, to develop and execute a plan to help make hospital culture more patient-centric?

- What are the best mechanisms to ensure that the Task Intensity Model gives way to some combination of AIDET and Empathetic Engagement?

- How do you handle the argument that this externally driven patient-experience initiative is costing the hospital too much time and money?

- What can you build on from the AIDET initiative that will help you address other obstacles to organizational-culture change at ABC Hospital?

Those of us who consult for a living face questions like these from our clients.

My team and I made several recommendations related to the implementation of AIDET. First, we stressed that hospital leaders should continue reinforcing AIDET as a basic foundation for staff-patient interactions. As part of that effort, we recommended sharing AIDET successes (e.g., via video, stories) with employees throughout the hospital. Training and coaching in AIDET should continue on a regular basis so that it becomes a routine part of staff-initiated interactions. Incentives and rewards should reinforce AIDET use. Second, we recommended heightening staff responsiveness to patient questions and concerns. Seeking answers to patient queries in a timely fashion, and accommodating patient requests when appropriate, should be part of each employee's job. On the one hand, staff members should be held accountable for their actions. On the other hand, when high workloads are perceived as "normal," staff and patients suffer and workplace realignment needs to occur. Finally, we recommended creating a series of new initiatives to highlight the importance of Empathetic Engagement between staff and patients, and among staff members. Staff-patient interactions are unlikely to become consistently empathetic, engaging, or patient-centered if interactions across the workforce do not become more collaborative and empowering.

By the way, what kind of staff-patient interaction model would you prefer if you were a patient? 


\section{References}

Alvesson, M. and D. Kärreman. 2011. Decolonializing Discourse: Critical Reflections on Organizational Discourse Analysis, Human Relations, 64(9): 1121-1146.

Balik B., J. Conway, L. Zipperer, and J. Watson. 2011. Achieving an Exceptional Patient and Family Experience of Inpatient Hospital Care. IHI Innovation Series white paper. Cambridge, MA: Institute for Healthcare Improvement.

Basso, K.H. 1972. 'To Give Up on Words': Silence in Western Apache Culture, In P.P. Giglioli, ed., Language and Social Context. New York, NY: Penguin Books, 67-86.

Boden, D. 1995. The Business of Talk: Organizations in Action. Blackwell Publishing.

Briody, E.K., R.T. Trotter, II, and T.L. Meerwarth. 2014. Transforming Culture: Creating and Sustaining Effective Organizations. New York, NY: Palgrave Macmillan.

Drew, P. and Heritage, J. 1992. Analyzing talk at work: an introduction, In P. Drew and J. Heritage, eds., Talk at Work: Interaction in Institutional Settings. Cambridge, UK: Cambridge University Press, 3-65.

Feirn, A., D. Betts, and T. Tribble. 2009. The Patient Experience:

Strategies and Approaches for Providers to Achieve and Maintain a Competitive Advantage. Deloitte Consulting LLP, www.deloitte.com/us/healthsciences

Foucault, M. 1977. Discipline and Punish: The Birth of the Prison. New York, NY: Vintage Books.

Merlino, J.I. and A. Raman. 2013. Understanding the Drivers of the Patient Experience. HBR Blog Network, September 17, blogs.hbr.org/2013/09/understanding-the-drivers-of-the-patientexperience/

Morris, M.A. 2012. Concise Dictionary of Social and Cultural Anthropology. Malden, MA: Wiley-Blackwell.

Sacks, H., E.A. Schegloff, and G. Jefferson. 1974. A Simplest Systematics for the Organization of Turn-Taking for Conversation, Language 50(4):696-735, December.

Sherzer, J. 1983. Kuna Ways of Speaking: An Ethnographic Perspective. Austin, TX: University of Texas Press.

Versel, N. 2014. Hospitals Focus on Patient Experience through Design. U.S. News and World Report. September 25, health.usnews.com/healthnews/hospital-of-tomorrow/articles/2014/09/25/hospitals-focus-on- 
patient-experience-through-design?page=3, accessed October 22, 2014.

Wasson, C. 2006. Being in Two Spaces at Once: Virtual Meetings and their Representation, Journal of Linguistic Anthropology, 16(1):103-130.

Elizabeth K. Briody, Ph.D., is a cultural anthropologist who has been engaged in cultural change efforts for over 25 years. She is founder and principal of Cultural Keys LLC which helps organizations transform their culture, reach their potential, and attract and retain new customers. She has worked in health care, manufacturing, consumer products, service industries, research institutions, and other industries in the U.S. and abroad. Her most recent book is co-authored with Gary Ferraro, The Cultural Dimension of Global Business (7th ed., Pearson, 2013). She may be reached at elizabeth.briody@gmail.com, http://culturalkeys.us. 